NBER WORKING PAPER SERIES

\title{
EFFECTIVE EXCHANGE RATE CLASSIFICATIONS AND GROWTH
}

Justin M. Dubas

Byung-Joo Lee

Nelson C. Mark

Working Paper 11272

http://www.nber.org/papers/w11272

\author{
NATIONAL BUREAU OF ECONOMIC RESEARCH \\ 1050 Massachusetts Avenue \\ Cambridge, MA 02138 \\ April 2005
}

We thank seminar participants at Notre Dame's Econ Brownbag workshop, the Kellogg Institute, and the NBER IFM Fall 2004 program meeting for useful comments. The views expressed herein are those of the author(s) and do not necessarily reflect the views of the National Bureau of Economic Research.

(C2005 by Justin M. Dubas, Byung-Joo Lee, and Nelson C. Mark. All rights reserved. Short sections of text, not to exceed two paragraphs, may be quoted without explicit permission provided that full credit, including (C) notice, is given to the source. 
Effective Exchange Rate Classifications and Growth

Justin M. Dubas, Byung-Joo Lee, and Nelson C. Mark

NBER Working Paper No. 11272

April 2005

JEL No. F30, F31, F41

\begin{abstract}
$\underline{\text { ABSTRACT }}$
We propose an econometric procedure for obtaining de facto exchange rate regime classifications which we apply to study the relationship between exchange rate regimes and economic growth. Our classification method models the de jure regimes as outcomes of a multinomial logit choice problem conditional on the volatility of a country's effective exchange rate, a bilateral exchange rate and international reserves. An 'effective' de facto exchange rate regime classification is then obtained by assigning country-year observations to the regime with the highest predictive probability obtained from the estimation problem. An econometric investigation into the relationship between exchange rate regimes and GDP growth finds that growth is higher under stable currency-value regimes. Significant asymmetric effects on country growth from not doing what is said are found for nonindustrialized countries. Countries that exhibit 'fear of floating' experience significantly higher growth.
\end{abstract}

Justin M. Dubas

University of Notre Dame

jdubas@nd.edu

Byung-Joo Lee

University of Notre Dame

lee.81@nd.edu

Nelson C. Mark

Department of Economics and Econometrics

University of Notre Dame

Notre Dame, IN 46556

and NBER

nmark@nd.edu 


\section{Introduction}

In this paper, we propose using a familiar econometric procedure to obtain de facto classifications of national exchange rate policy. We then use this de facto classification to investigate the role of exchange rate regimes in growth and whether differences between what countries say and what they do matter for growth. Accurate and meaningful classifications of a country's currency management are crucial for assessing the merits between fixed and floating exchange rates. Until recently, empirical research employed the de jure classification, which largely reflects the self-reported regime submitted by a country's central bank to the International Monetary Fund. However, observers have noted that for many countries, de facto management of currencies seems at odds with their de jure management. ${ }^{1}$ As a result of such discrepancies, the de jure classification has been viewed as unsatisfactory for assessing the role of exchange rate stability in economic performance and has motivated researchers to propose de facto exchange rate classifications that are based on observed properties of the foreign exchange market data. Influential contributions include the pioneering work of Reinhart and Rogoff (2004) (hereafter RR) and Levy-Yeyati and Sturzenegger (2003) (hereafter LYS). RR argue that a natural classification of exchange rate regimes should be based on the behavior of the parallel market exchange rates on the grounds that they better reflect underlying market and monetary conditions than do the country's official exchange rates. LYS, on the other hand, advocate the use of a k-means cluster sorting algorithm to assign countries to the various exchange rate regimes. ${ }^{2}$

The idea that underlies our classification method goes like this. It must be the case that many countries actually do what they say and that the regime they report results

\footnotetext{
${ }^{1}$ Reference to potential inconsistencies between de jure and de facto regimes dates back at least to Frankel and Wei (1995). While some de jure exchange rate fixers may appear to be de facto floaters due to frequent changes in their peg, others that are de jure floaters appear to be de facto fixers since they maintain very stable exchange rates-a phenomenon that Calvo and Reinhart (2002) refer to as 'fear of floating.'

${ }^{2}$ Assessing the role of a country's exchange rate regime in economic performance is an active area of research. The LYS classifications have been used by Juhn and Mauro (2002), who explore the long-run determinants of exchange rate regimes, Bordo and Flandreau (2001), who examine the link between financial depth and exchange rate regimes, Frankel, Schmukler and Serven (2002) who use it to examine the link between regime choice and local interest rate sensitivity, Edwards and Levy-Yeyati (2003) and Broda (2004), who analyze the impact of terms of trade on economic performance under different regimes. Both the LYS and RR regime classifications are used by Alesina and Wagner (2003) to find the politico-economic institutional qualities of countries with different exchange rate regimes. RR is employed by Reinhart, Rogoff and Savastano (2003), who attempt to correlate the degree of exchange rate flexibility and degree and type of financial dollarization and Rogoff et.al (2004), who explore economic performance under alternative regimes.
} 
from thoughtful assessments of perceived, economically relevant exchange rate stability. Under this supposition, we model the de jure responses econometrically and use estimation of the systematic component of the response to create the de facto classification. The unsystematic component-the error term-thus captures the unobservable factors that influence some countries to announce an exchange rate policy that differs from the one that is implemented.

The model that we employ for this purpose views the de jure classifications as outcomes of a multinomial logit choice problem conditional on measures of volatility in the country's effective exchange rate, its bilateral exchange rate against an appropriate anchor currency, and international reserves. As one of the determinants of the choice problem is the volatility of the country's effective exchange rate, we refer to our de facto regime assignments as the 'effective' exchange rate regime classification. Country-year observations are then assigned to the regime with the highest predictive probability, which we obtain from the multinomial logit, to create a de facto 'effective' exchange rate regime classification. ${ }^{3}$ This approach has three attractive features. First, classifier judgment is required primarily in selecting the variables to be included in the econometrics. Modifying and updating the classifications becomes straightforward since one only needs to adjust or update the data employed in estimation of the choice problem. Second, the optimization criteria of our approach is familiar as it is based on the likelihood principle and has well-known properties. Here, the difficulties associated with 'inconclusive' observations is much less problematic. Third, it is feasible with our method to include a potentially large number of regime determinants. ${ }^{4}$

A novel aspect of our paper worth emphasizing is our use of effective exchange rate volatility as one of the classification determinants whereas previous research has typically emphasized the properties of a bilateral exchange rate against an anchor currency. For a small open economy in a multilateral world, there are at least three reasons why the behavior of the effective exchange rate might influence the generalized assessment of currency stability. First, consider countries that maintain a hard bilateral peg. Unless

\footnotetext{
${ }^{3}$ The predictive probabilities can also be used to construct the mean regime choice to serve as a continuous index of the country's exchange rate regime.

${ }^{4}$ Limiting the role of the classifier's judgment can be an advantage over RR's methodology: Because it is heavily dependent on their judgment, future research with their classifications may require RR to provide updates. The econometrics of our approach has some advantages over LYS's cluster analysis. LYS's method attempts to sort countries into exchange rate regimes by minimizing the unweighted average of within group sum of squared deviations from the group mean over each country characteristic yielded 698 inconclusive country-year observations and is feasible only when the set of regime determinants is small. Moreover, the optimality properties of their method are not well understood.
} 
they trade exclusively with the anchor currency country or within a bloc that pegs to the same anchor, the effective exchange rate will exhibit more instability than the bilateral exchange rate. Argentina is a case in point. Its operation of the currency board made it a hard fixer to the US dollar. However, in 2000 only 16 percent of its trade was with the US whereas 27 percent was with Brazil, 7 percent with Chile and 4 percent with Germany. As a result, its effective exchange rate during this time exhibited substantially more instability than the peso-US dollar rate. ${ }^{5}$ Second, consider those countries that engage in relatively little trade with the anchor country. For these countries, the instability in the bilateral rate against the anchor may be relatively unimportant. In fact, we find that in approximately half of the observations the volatility of the effective exchange rate lies below that of the bilateral exchange rate. Third, the multilateral approach to assessing exchange rate stability can be motivated as central banks increasingly diversify their reserve holdings away from the US dollar denominated assets, as recently announced by the Bank of Korea. ${ }^{6}$

Having obtained these effective classifications, we use them to study the impact of exchange rate regimes on GDP growth. Economic theory does not have clear-cut predictions about how the exchange rate regime affects growth. Typically, analysis of the trade-offs associated with fixed versus flexible exchange rates are conducted in terms of the regime's effect on stabilization and trade and their effect on growth is imperfectly understood. Empirical findings on relation between the exchange rate regime and output growth reported in the literature are also mixed. Broadly speaking, Ghosh et. al. (2002) who use the de jure classifications, and RR report that higher growth is associated with the more stable currency value regimes. LYS, on the other hand, find that higher growth is associated with more exchange rate flexibility where the highest growth rate is associated with floaters, followed by fixers then intermediates. When we estimate panel data growth regressions using the effective regimes and a standard set of growth determinants, we find that higher growth is associated with fixed exchange rate regimes. This result is driven mainly by the experience of nonindustrialized countries since we find that industrial country growth is not significantly related to the exchange rate regime.

\footnotetext{
${ }^{5}$ Over our full sample (1971 to 2002), Argentina's effective exchange rate volatility measured as the annualized standard deviation of monthly percent changes, was 25.9 percent whereas the volatility of the peso-dollar rate was 18.3 percent. While for hard fixers, the effective exchange rate is clearly more volatile than the bilateral exchange rate we find in general that there is no presumption regarding the volatility ranking between bilateral and effective exchange rates. We have about as many of our country-year observations exhibit effective exchange rate volatility that lies below bilateral exchange rate volatility as those that lie above.

${ }^{6}$ New York Times, Feb 22, 2005.
} 
We also examine whether differences between what a country says and what it does matters for growth. Genberg and Swoboda (2004) hypothesize an asymmetry between countries that say they fix but float and for countries that say they float but fix. A de jure fixer that floats de facto is breaking a promise to maintain a stable currency value and might be expected to be punished with inferior growth. On the other hand, a de jure floater that fixes de facto - one that exhibits fear of floating - does not violate any such agreement. Instead, it comes in above expectations by delivering exchange rate performance that is superior to what was promised and might be expected to be rewarded with superior growth outcomes. We find evidence in support of these hypothesized asymmetries. For nonindustrialized countries, we find growth to be significantly higher for de jure floaters who effectively fix de facto. These countries therefore have a direct motive to display fear of floating if it results in significantly faster growth.

The remainder of the paper is organized as follows. Section 1 presents an informal analysis of bilateral and effective exchange rates that highlights the difference in behavior between them. Section 2 presents our regime-choice model and discusses features of our effective exchange rate classifications. Section 3 contains our analysis of the relationship between the exchange rate regime and growth and Section 4 concludes. A description of the data, variable construction and sources is contained in the Appendix.

\section{Properties of effective and bilateral exchange rates}

Our task, as well as the task confronting the authorities, is to classify country exchange rate policy according to the de jure categories [see Ghosh et. al. (2000)] which we arrange in order of increasing stability.

1. Independently floating

2. Managed floating

3. Adjusted according to a set of indicators

4. Cooperative arrangements

5. Limited flexibility

6. Currency peg 
Typically, researchers have emphasized the properties of the bilateral exchange rate of an anchor currency in connection with regimes classification. ${ }^{7}$ The informal comparison between effective and bilateral nominal exchange rates presented in this section shows that a very different picture about both the level and the volatility of a country's currency value can emerge depending on whether it is viewed through the lens of a bilateral or a multilateral exchange rate. Their properties are sufficiently different for us to conclude that the effective exchange rate contains information beyond that contained in the bilateral exchange rate that is relevant for a country in announcing the de jure regime that describes how it manages its currency.

Anchor currencies for bilateral exchange rates are either the U.S. dollar, the British pound, the French franc, or the German mark. For this, we follow the country assignment used in LYS. Because effective exchange rate series do not exist for most nonindustrialized countries, these data are constructed by us. ${ }^{8}$

We divide our discussion between an examination of the volatility of the alternative exchange rate measures and a comparison of their dynamics.

\subsection{Volatility}

We measure volatility as the annual sample standard deviation of monthly percentage changes in the exchange rate. The effective and bilateral exchange rate will exhibit the same degree of stability only if the country does all of its trade with the country to which it fixes or trades only with countries that also fix to the same currency. Such may approximately be the case for the Bahamas, which is a hard fixer to the US dollar and who in 2000 did 86 percent of its trade with the U.S., but this is an extreme case. Other counties that pegged to the dollar include Panama, who in 2000 conducted 40

\footnotetext{
${ }^{7}$ See Calvo and Reinhart (2002), Reinhart and Rogoff (2002), Levy-Yeyati and Sturzenegger (2003), Shambaugh (2004).

${ }^{8}$ We begin with aggregated trade data obtained from the United Nation's Comtrade database. These are imports and exports according to SITC rev.1 commodity classification or SITC rev.2 data when SITC rev.1 was not available for a particular country/year. For each reporting country $i=1, \ldots, 180$ and year $(t=1971, \ldots, 2002)$, set of weights are formed by taking trade between country $i$ and $j$ as a fraction of country $i$ 's total trade for that year. These weights are used to construct the geometric average of respective bilateral nominal exchange rates and normalized such that their value in December 2000 is 100 to form the effective exchange rate. The NEER for country $i$ at month $m$ of year $t$ is constructed as: $N E E R_{i m_{t}}=\prod_{j=1}^{N}\left(B N E_{i j m_{t}}\right)^{w_{i j t}}$ where $N E E R_{i m_{t}}$ is the nominal effective exchange rate for country $i$ at month $m$ of year $t, B N E_{i j m_{t}}$ is the nominal bilateral exchange rate between country $i$ and $j$ at month $m$ of year $t$ calculated as the relative rates per U.S. dollar, $w_{i j t}$ is the trade weight between county $i$ and $j$ at year $t$, and $N$ is total number of countries.
} 
percent of its trade with the U.S., 7 percent with Ecuador, 7 percent with Venezuela and 5 percent with Japan. Further down the line is China, which in 2000 did 19 percent of its trade with Japan, 17 percent with the U.S., 12 percent with Hong Kong, 8 percent with Korea and 5 percent with Germany. ${ }^{9}$ The presumption is that the volatility of the effective exchange rate will exceed that of the bilateral exchange rate for countries that maintain a hard bilateral peg.

Figure 1 presents scatter plots of the volatility of countries' effective and bilateral exchange rates. Hard bilateral fixers should appear below the 45 degree line and roughly half of the countries fit this pattern, as effective exchange rate volatility exceeds bilateral exchange rate volatility in 92 of the 172 countries for which we have data. Of these, 12 are OECD members.

Somewhat surprisingly, about half of the sample lie above the 45 degree line. For these countries, bilateral exchange rate volatility may be relatively unimportant if they do relatively little trade with the anchor country. As the data points appear randomly distributed about the 45 degree line, there seems to be no presumption as to whether effective exchange rate volatility dominates bilateral exchange rate volatility. ${ }^{10}$

\subsection{Dynamics}

We compare the dynamic behavior between bilateral and multilateral exchange rate measures by regressing changes in the effective exchange rate on changes in the bilateral exchange rate at various horizons as well as in the levels of the observations. The levels observations are standardized so that the slope coefficient gives us an estimate of the correlation. ${ }^{11}$

\footnotetext{
${ }^{9}$ In 2000, the U.S.'s major trading partners were Canada (21 percent) and Mexico (13 percent), Japan (11 percent) and China (6 percent).

${ }^{10}$ Countries whose effective exchange rate volatility exceeded bilateral exchange rate volatility by 50 percent (excluding those who maintained a hard fix throughout the sample) include Angola, Armenia, Austria, Azerbaijan, Bahrain, Belg. Lux, Belize, Cambodia, Chad, Comoros, Congo, Cyprus, Czecho, Estonia, Finland, Georgia, Germany, Guinea Bis, Haiti, Kuwait, Lao, Latvia, Libya, Lithuania, Maldives, Mauritania, Neth.Ant.A, Netherland, Oman, Qatar, Saudi Arab, Singapore, Slovakia, Somalia, Suriname, Switzerland, UAE and USA. Countries whose bilateral exchange rate volatility exceeded effective exchange rate volatility by 50 percent or more include Australia, Bangladesh, Benin, Bolivia, Botswana, Burkina Faso, Cent.Af.Rep.,China, Macao, Cote d'Ivorie, El Salvador, Ethiopia, Gambia, Guatemala, Guinea, Iceland, India, Ireland, Jordan, Kazakhstan, Kiribati, Kyrgyzstan, Lesotho, Mali, Mongolia, Namibia, New Zealand, Niger, Poland, Portugal, Rwanda, SaoTomePri, Senegal, Seychelles, Swaziland, Syria, Tonga, TrinTobago, Tunisia, Uganda and Ukraine.

${ }^{11}$ We standardize the levels observations because the effective exchange rate is actually an index and is scaled differently from the bilateral exchange rate.
} 
Table 1 shows the percentage of countries for which slope coefficient estimates indicate dynamic divergence between effective and bilateral exchange rates. The coefficients for most countries exhibit large deviations from unity across the various horizons. At the monthly horizon most of the slope coefficients are positive but very small in magnitude. However, for many countries, the monthly change in the bilateral exchange rate is negatively correlated with the change in the effective exchange rate since negative point estimates are obtained for 21 of 157 available countries (13.4 percent). The discordance between the dynamics of effective and bilateral measures of the exchange rate tends to increase with the time horizon: Slope coefficient estimates are negative for 16 (of 152 available) countries for annual percent changes, 21 (of 138 available) countries at the 4year horizon, and for 49 (of 157 available) countries when the regressions are performed on exchange rate levels.

Looking only at the correlation between changes in the effective and bilateral exchange rates will in some cases obscure an underlying divergence in their trends, which is illustrated in the case of Denmark. Figure 2 shows plots of the monthly percent change, 4-year percent change and the levels of effective and bilateral exchange rates for Denmark. ${ }^{12}$ While there has been an effective appreciation of the krone over the sample period and a bilateral depreciation with respect to the deutschemark, first-differences in the two exchange rate measures are positively correlated. ${ }^{13}$ The effective and bilateral exchange rates for Canada and many European countries exhibit similar patterns (not shown).

The descriptive statistics that we report combine experiences across regimes ranging from hyperinflation to currency board hard fixes. What these very aggregative summary statistics on volatility suggest, however, is that a very different picture about exchange volatility exposure emerges when viewed through the lens of effective rather than bilateral exchange rates.

\footnotetext{
${ }^{12}$ The reciprocal of nominal effective exchange rates are plotted. Therefore, the decrease of NEER represents appreciation of effective rate. Both effective rates and bilateral rate are normalized in the plot.

${ }^{13}$ Two trend-stationary series $\left\{x_{t}\right\}$ and $\left\{y_{t}\right\}$ can trend in opposite directions and have positively correlated changes if the times when both series increase $x_{t}$ experiences large changes and $y_{t}$ experiences small changes and vice-versa when both series decrease. Suppose that $y_{t}=\alpha(1-\rho)+\rho y_{t-1}+\varepsilon_{t}$, $x_{t}=\beta(1-\gamma)+\gamma x_{t-1}+v_{t},\left(\varepsilon_{t}, v_{t}\right)^{\prime} \stackrel{i i d}{\sim}(0, \Sigma), \Sigma_{11}=\Sigma_{22}=1, \Sigma_{12}>0,0<\rho, \gamma<1$. Let $\alpha<0$ and $\beta>0$ so that they trend in opposite directions. Denoting the deviation from the mean with a ${ }^{6}$, , it follows that the covariance between changes in $x_{t}$ and $y_{t}$ is $E\left(\Delta \widetilde{y}_{t} \Delta \widetilde{x}_{t}\right)=(1-\gamma \rho)^{-1} \Sigma_{12}(2-\gamma-\rho)>0$.
} 


\section{Effective exchange rate regime classifications}

We present the discrete choice model for the de jure classifications in section 2.1. Section 2.2 discusses general features of our effective exchange rate classifications with comparisons to alternative classifications. In section 2.3, the comparison among the alternative classifications is specialized to a selected set of countries.

\subsection{Modeling regime choice probabilities}

The approach we follow is commonly employed to model household revealed preferences from survey responses. We begin with a latent variable model of the determination of the de jure classifications where the 'true' exchange rate regime perceived by the country's monetary authorities $R_{i j t}^{*}$ are given by

$$
R_{i j t}^{*}=x_{i t}^{\prime} \beta_{j}+\epsilon_{i j t}
$$

$x_{i t}$ is a vector of the country's characteristics and the error $\epsilon_{i j t}$ has an extreme value distribution. Let the revealed de jure classifications of the country's exchange rate policy be $R_{i j t}$. Then the probability $p_{i j t}$ that country $i=1, \ldots N$ reports itself to pursue policy $j=1, \ldots 6$ in year $t$ is the conditional multinomial choice probability

$$
p_{i j t}=\frac{\exp \left(x_{i t}^{\prime} \beta_{j}\right)}{\sum_{k=1}^{6} \exp \left(x_{i t}^{\prime} \beta_{k}\right)}
$$

where $\beta_{j}$ is a vector of coefficients associated with regime $j$ which we estimate as a random-effects panel regression. ${ }^{14}$

The regime categories in the multinomial logit specification are unordered. This has an important advantage over an ordered response model in our context because it allows for coefficient heterogeneity across regimes. That is, we allow the impact of country $i$ 's $k$-th characteristic on the choice probability to differ across policy choices whereas an ordered response model imposes homogeneity restrictions on the coefficients across regimes. With our emphasis on measurement as opposed to inference, we choose to adopt the less restrictive approach.

The country $i$ characteristics that we use to form $x_{i t}$ are i) the volatility of the effec-

\footnotetext{
${ }^{14} \mathrm{~A}$ normalization with respect to one of the regimes is required for identification. We use regime 5 , which is the regime that occurs most frequently, for the normalization.
} 
tive exchange rate, ii) the mean absolute change (an alternative measure of volatility) of the effective exchange rate, iii) the volatility of the bilateral exchange rate, iv) the mean absolute change in the bilateral exchange rate, and v) the volatility of the country's international reserves. ${ }^{15}$ Reserve volatility is predicted to be directly related to the 'fixity' in the exchange rate regime, the idea being that high reserve volatility is associated with frequent foreign exchange market intervention and active management.

We use the estimated parameters $\widehat{\beta}_{j}, j=1 \ldots 6$, to obtain the predictive probability that a country with characteristic vector $x_{i t}$ will exhibit exchange rate policy $j$. We can then assign the regime with the highest predictive probability to the country-year observation. Alternatively, we can use the predicted mean value to form a continuous exchange rate stability index $\operatorname{IDX}_{i j t}=\sum_{j=1}^{6} j p_{i j t}$.

\subsection{Some properties of effective regime classifications}

The distribution of the classifications generated by alternative specifications of the country characteristics is displayed in Table 2. Our preferred classification, described under the heading 'combined,' employs both measures of effective exchange rate dispersion (volatility and mean absolute deviation), the mean absolute change in the bilateral exchange rate and international reserve volatility. ${ }^{16}$ It can be seen that most of the country-year observations lie towards the stable exchange rate region of the spectrum being classified into categories 4 (cooperative) and 5 (limited flexibility). 64 observations are classified as hard fixers. The next largest classification is category 1 (independently floating), which forms $17 \%$ of the observations. Under the column heading 'drop bilateral,' we list the distribution of classifications generated with the volatility and mean absolute change in the effective exchange rate and reserve volatility (properties of the bilateral exchange rate omitted). Here, we obtain nearly the same number of free-floaters, but many more fixers (categories 5 and 6 ). The tendency to classify country-year ob-

\footnotetext{
${ }^{15}$ Volatility is measured as the annual sample standard deviation of the monthly percentage change in the respective variables. The mean absolute change for year $t$ is similarly computed from the annual average of monthly percentage changes. We note also that interest rate volatility is also an important characteristic to determine exchange rate regimes. However, due to the data availability problem, we lost significant number of observations in estimation, and we dropped the interest rate volatility from the estimation problem.

${ }^{16}$ The individual coefficient estimates from the multinomial logit do not have natural interpretations in this context and are not reported. We originally performed estimation using all five variables but because bilateral exchange rate volatility and mean absolute change measures are highly correlated (0.94) we dropped the volatility measure. Very similar results are obtained by keeping bilateral volatility and dropping the bilateral mean absolute change.
} 
servations as fixers is even more pronounced when we omit the effective exchange rate and use the volatility and mean absolute change in the bilateral exchange rate along with reserve volatility. These classifications are shown under the column heading 'drop effective.' Thus using only the effective exchange rate or bilateral exchange rate results in a dearth of countries being classified in the middle.

Figure 3 plots the evolution of our preferred effective classifications along with the de jure, LYS, and RR classifications. ${ }^{17}$ In the de jure classifications, the sample begins with nearly all countries reporting to be fixers (categories 5 and 6). This proportion has declined steadily over time with an increasing number of countries having moved towards reporting themselves to be pursuing a policy of flexible exchange rates (categories 1 and 2 ). The 'hollowing out of the middle' phenomenon-the decline in the number of countries reporting intermediate regimes-is seen only in the de jure classification.

The evolution of effective pure floaters is similar to that of de jure floaters. Very few country-year observations are classified as effective hard fixers. Most observations are placed in categories 1,4 , and 5 with a relatively large proportion of category 5 regimes (limited flexibility). There was a tendency to move away from fixing in the 1970s but the proportion of fixers has remained stable in the 1980s and 1990s. Interestingly, looking at effective categories 5 and 6 to RR's category 5 and comparing effective categories 1 and 2 to RR's categories 1 and 2, the effective classification exhibits a higher correspondence to RR's 'natural classification' than it does either to LYS or the de jure classifications. The distribution over time of the RR classification is relatively stable with many more intermediate regimes than our effective classification. One possible reason for this stability is that RR employ a 5-year window for computing exchange rate variability whereas we (and LYS) employed a one-year window. The LYS classification consistently classifies the majority of observations into the fixed category. More than 70 percent of LYS observations were classified as fixers in 1974 and approximately 55 percent were still classified as fixers in 2000 .

Table 3 shows the unconditional correlation matrix for the alternative classifications and the country characteristics that we used to produce the effective classification. Among alternative classifications, our effective classifications are most highly correlated

\footnotetext{
${ }^{17}$ Our effective classifications are not directly comparable to RR nor LYS since they do not provide a 6 -way classification. For RR, we reversed and renumbered their 5-way classification broken down as 1) Freely falling, 2) Freely floating, 3) Managed floating, 4)Limited flexibility, 5) Peg. For LYS, we examine their 4-way classification broken down as 1) Flexible, 2) Dirty Float, 3) Crawling Peg, and 4) Fixed. Both RR and LYS have a category for observations that are deemed 'inconclusive,' which we omitted in drawing the figures.
} 
with RR (0.53) and are least correlated with the IMF de jure classifications (0.32). As expected, the effective regime classifications are negatively correlated with both measures of effective exchange rate variability as are the RR classifications. Neither LYS nor the de jure classifications appear to be systematically related to volatility in the effective exchange rate.

None of the four classifications are very correlated with reserve volatility. The correlation is slightly positive for the effective, de jure and LYS and slightly negative for RR. Increasing flexibility in the effective and RR classifications are associated with higher bilateral exchange rate variability. The correlations between these variables and the de jure and the LYS classifications are relatively small.

Table 4 presents cross tabulations between the effective classification, the de jure, LYS and RR classifications. Looking at the first panel of the table, a perfect correspondence between what countries say and what they do would result in nonzero values only on the diagonal entries. Divergence takes the form of countries that say they float but are de facto fixers (fear of floating) and those that say they fix but are de facto floaters. As can be seen, of 853 de jure floaters (categories 1-2), fear of floating is observed in 265 observations that are effectively classified as fixers (categories 5 and 6) whereas 84 out of 1035 de jure fixers (categories 5-6) are effectively classified as floaters.

There are some notable differences between our effective classifications and LYS. 63 LYS floaters (category 1) are classified as effective fixers (categories 5 and 6) and 74 LYS fixers were classified as effective floaters (categories 1 and 2). The cross-tabulation with $\mathrm{RR}$ is relatively concentrated on and just below the diagonal. As we've seen before, the overall correlation between the effective and RR classifications are relatively high which can be seen in the cross-tabulation table.

Table 5 reports the distribution of the effective classifications across industrialized and nonindustrialized countries. For nonindustrialized countries, most country-year are assigned to category 5 , reflecting substantial exchange rate stability. For industrialized countries, approximately 15 percent of the country-year observations are assigned as 'independently floating' and roughly 80 percent are assigned to relatively stable exchange rate categories 4 and 5 .

The table also shows the regime assignments broken down according to whether the country experience a crisis during the sample year. A crisis is said to occur in year $t$ if the country experienced a month-to-month change in its effective exchange rate exceeding 25 percent. Of 5760 country-year observations, there were 434 crisis observations, 424 of which occurred in nonindustrialized countries and 10 for industrialized countries. We 
note that our classification methodology does not automatically consign crisis observations to a free float since as can be seen, a relatively large share of crisis country-year observations continue to be grouped in categories 4 and above (28 percent).

\subsection{Comparison of alternative classifications for selected coun- tries}

How do the alternative classifications compare for specific countries? Table 6 gives the evolution of exchange rate regime classifications for a set of emerging market economiesArgentina, Mexico, Peru, and Korea. For Argentina, there is some disagreement across the classifications in the early 70s. In the late 70s, our method and RR classifies it as a floater whereas LYS classifies it as a fixer. In the 90s the country is generally classified as a fixer by each of the classification methods. In 1993, our method classifies Argentina as a floater whereas the de jure, LYS, and RR methods classify it as a fixer. Ostensibly, the reason that our method gives this result is that Brazil, a large trading partner of Argentina's was heading into a period of high inflation and the real depreciated by 2000 percent against the dollar. This depreciation was reflected in instability of the effective exchange rate. $^{18}$

For Mexico, the effective classification largely agrees with RR until the mid 1990s. In the 1970s, LYS systematically classifies the peso to be more flexible than the assignment given by either RR or the effective classification. Similarly, for Peru, the effective classification is largely consistent with RR. For Korea, all three de facto classifications are quite similar with each other. Throughout the sample, they consistently view the won as being more stable than its de jure floater classification. Korea thus appears to be a classic example of fear of floating, especially after the crisis of 1997.

We note that each of the de facto classifications exhibit periods of volatility. The RR regimes for Argentina jump from 2 to 6 back to 2 from 1984 to 1986. LYS's classification for Peru jumps from 5 to 2 to 4 between 1974 and 1976. The effective regimes switch from 5 to 1 back to 5 between 1992 and 1994. However, our methodology also allows us to use the estimated choice probabilities construct a continuous index of exchange rate stability from the mean regime value,

$$
\operatorname{IDX}_{i t}=\sum_{k=1}^{6} k \widehat{p}_{i k t} .
$$

\footnotetext{
${ }^{18}$ The 1993 predictive probability for floating is 0.39 which is not particularly high. The respective 1993 predictive probabilities are $p_{1}=0.39, p_{2}=0.23, p_{3}=0.04, p_{4}=0.00, p_{5}=0.20, p_{6}=0.14$.
} 
Being a mean value, the index is seen to exhibit less volatility and fewer extreme values than the classification data.

Table 7 displays alternative classifications for the US, France, Japan, and Switzerland. The effective classification places the dollar in an intermediate regime and characterizes it as being somewhat more stable than RR or LYS. For France, our effective classification corresponds closely to RR by assessing the franc to be a relatively stable currency whereas LYS often classifies the franc to be relatively flexible. The effective classification for Switzerland corresponds more closely to LYS than it does to RR and all of the de facto methods classify this country's exchange rate as more stable than its de jure classification. From 1973 onwards, Switzerland can consistently be described as having a fear of floating. For Japan, our effective classification is largely in agreement with RR and its de jure classification as a floater whereas LYS tends to classify its exchange rate as being somewhat more stable.

\section{$3 \quad$ Exchange rate regimes and growth}

In this section, we employ the effective exchange rate classifications to study the relation between the exchange rate regime and GDP growth. Our analysis centers on two questions. In subsection 3.1, we revisit the question of which exchange rate regime - fixed, flexible, or something in between - is associated with the highest rates of growth. In subsection 3.2 we examine whether differences between what a country says to be its exchange rate policy (its de jure classification) and what it does (its de facto classification) matter for growth.

\subsection{Exchange-rate stability and growth}

Although there exists an extensive literature that studies the choice between fixed and flexible exchange rates, economic theory does not have clear-cut predictions about the impact of the exchange rate regime on growth. This is partly because the tradeoff between fixed and flexible exchange rates is usually evaluated in terms of the stabilization and trade promoting properties of alternative monetary arrangements and the effect that smoothing out cyclical fluctuations and trade creation have on growth may be indirect. Frankel (2003) discusses the tradeoffs along four main points.

For his four reasons to fix we begin with the observation that stable exchange rates provide a nominal anchor for monetary policy. A policy of fixing the exchange rate 
can impose the required discipline on the monetary authorities to keep inflation under control. Second, by reducing uncertainty, maintaining stability in the currency's value can promote increased international trade and investment. Third, maintaining a fix precludes competitive depreciations which can have a destructive effect on trade. Fourth, the exchange rate will not be driven by speculative bubbles if it is fixed.

He also discusses four reasons why countries may want to promote exchange rate flexibility. First, by allowing an independent monetary policy, policy makers retain a tool to offset adverse country shocks. Second, a flexible exchange rate provides an avenue for required relative price adjustments to trade shocks. Third, because a floating rate regime breaks the connection between international reserves and credit creation, it allows the central bank to be an effective lender of last resort and to retain seignorage revenues. Fourth, the central bank would not be the target of a speculative attack on its currency.

The weight of the evidence points towards high growth being associated with more stable exchange rates. Some indirect evidence is provided by Frankel and Romer (1999) who find that an increase in trade has a significant positive effect on per capita income, and Frankel and Rose (2002) who present evidence that trade benefits when exchange rates are stabilized. The estimates from the latter paper imply that membership in a currency union can raise trade with other union members by a factor of $3 .^{19}$ In research that directly examines the relation between exchange rate regimes and growth, Ghosh et. al. (2000) and RR generally find that higher growth is associated with exchange rate stability. Ghosh et. al. estimate the growth-rate ordering of de jure regimes (from highest to lowest) as i) intermediate regimes, ii) fixers, then iii) floaters while RR report a growth-rate ordering of i) limited flexibility, ii) freely floating, iii) managed float and iv) peg.

LYS, on the other hand, find that the highest growth rates are associated with floaters, followed by fixers then intermediate regimes. Their results are driven in largely by the experience of nonindustrialized countries-the growth rate of nonindustrialized LYS floaters is approximately 1.1 percent higher than LYS intermediate and fixer countries. Edwards (2001), although analyzing a much smaller set of countries, finds that countries that have 'dollarized' have grown more slowly than nondollarized countries.

In our analysis, we follow the literature by collapsing our six-way effective exchange rate classification into a three categories by combining categories 1-2 (floaters), 3-4

\footnotetext{
${ }^{19}$ Klein (2002) and Klein and Shambaugh (2004) find the effect on trade creation to be somewhat smaller.
} 
(intermediates), and 5-6 (fixers). We also include an analysis with the LYS classifications for comparative purposes since the effective classifications contrasted sharply with those.

Table 8 provides a first look at the data by reporting mean GDP growth and volatility sorted by exchange rate regime. For effective regime classifications, intermediate regime countries have the highest mean growth rate. Non industrialized countries with an effective intermediate classification also have the lowest volatility in GDP growth. As a group, effective fixers have the second highest growth rate and effective floaters had the lowest growth rates. LYS floaters, on the other hand, have the highest mean growth and the lowest volatility while LYS intermediates have the lowest mean growth rate. Among industrialized countries, the highest mean growth rate is achieved by LYS fixers. Among nonindustrialized countries, the highest mean growth rate is experienced by LYS floaters.

We now proceed to an econometric investigation. Our strategy is to consider regressions of per capita growth on a set of growth control variables and a set of exchange rate regime dummies. It is well established that investments in physical and human capital, good macroeconomic policies, exposure to trade, and some government spending are factors that are conducive to growth. Thus, our control variables consist of i) initial year GDP, ii) initial year population, iii) population growth, iv) the investment to GDP ratio, v) secondary education attainment, vi) a political indicator of civil liberties, vii) trade openness, viii) the change in the terms of trade, ix) dummies for transitional economies, $\mathrm{x}$ ) regional dummies for Latin America and Africa, and xi) time-specific dummies. Exchange rate regime 1 is taken as the base, so growth effects implied by coefficients on exchange rate regime dummies are relative to the growth rate of floaters. ${ }^{20}$

We estimate random-effects panel regressions and report the results in Table 9. To economize on space, we do not report coefficient estimates for the auxiliary controls. Here, we find that the highest growth rates are associated with de facto fixers. With all countries in the sample, the coefficient on the fixer dummy is significant and we estimate that effective fixers grow a bit more than 1 percent faster than effective floaters. For industrialized countries, the coefficients on the regime dummies are positive and suggest slower growth for effective floaters than effective intermediates and fixers, but these estimates are not statistically significant. For nonindustrialized countries, we obtain a significant estimate of the coefficient on the fixer dummy. If this is a causal relationship, our estimates would imply that switching from a float to a fix would increase per capita growth by 1.3 percent .

\footnotetext{
${ }^{20}$ These controls are generally the same ones employed by LYS.
} 
The estimates suggest a monotone relationship between exchange rate stability and growth. Additional evidence along these lines can be obtained by replacing the regime dummies with our index of exchange rate stability, IDX $_{i t}$. When we do so, we obtain positive point estimates in the regressions that are significant in the full sample and for nonindustrialized countries. A unit increase in the stability index (higher means more stability) is associated with nearly a $\frac{1}{2}$ percent increase in per capita growth.

The contrast between our results and LYS is primarily due to differences between our regime classifications and not in the data since we are able to qualitatively replicate LYS's results with our data. ${ }^{21}$ Using the LYS classifications in growth regressions for nonindustrialized countries, growth for intermediate regimes are significantly lower at the $10 \%$ level than growth for floaters and the coefficient on LYS fixers is negative but insignificant. Their classification method assigns a larger proportion of country-year observations in the fixer category than does the effective classification used in this paper.

\subsection{Words, actions, and growth}

In this section, we investigate whether the difference between what a country says and what it does matters for growth. In this analysis, we assign country-observations into 4 words and action categories.

i) $\{$ de jure floaters $\cap$ de facto floaters $\}$,

ii) $\{$ de jure fixers $\cap$ de facto fixers $\}$,

iii) $\{$ de jure floaters $\cap$ de facto fixers $\}$,

iv) $\{$ de jure fixers $\cap$ de facto floaters $\}$.

Countries in categories i) and ii) do what they say. Countries in categories iii) and iv) do not. Calvo and Reinhart (2002) present systematic study of countries in category iii)countries which they refer to as having a 'fear of floating.' Fear of floating helps to explain the 'hollowing-out of the middle' hypothesis-that according to de jure classifications, countries are increasingly adopting either the extremes of fixed or floating exchange rates and are abandoning intermediate regimes. They conclude through examination of

\footnotetext{
${ }^{21}$ There are some differences between our analysis and LYS's. First, as we were unsuccessful in obtaining LYS's data, we constructed our own. Variables were constructed by conforming as close as possible to descriptions in LYS. Second, LYS do not exactly describe their econometric specification so there may be slight differences between our estimation methods.
} 
the bilateral exchange rate to an anchor currency, reserves, and interest rates that de facto hollowing-out is much less pronounced.

Genberg and Swoboda (2004) hypothesize a performance asymmetry for countries that do not do as they say. Category iv) countries have breached a commitment to maintaining exchange rate stability and countries that fall into this category are hypothesized to suffer inferior economic outcomes. Fear of floating countries (category iii) on the other hand have not broken any such commitment. Because they deliver better exchange rate performance than promised, they may be expected to be rewarded by superior growth performance.

The evolution of the distribution of observations across categories is shown in Table 10. In panel $\mathrm{A}$, de facto regimes are given by the effective classifications and in panel B, they are given by the LYS classifications. For both classifications, the proportion of countries that fear floating has steadily increased over time, although the proportion of effective fear of floating is consistently higher than the proportion of LYS fear of floating. While fear of floating has become increasingly prevalent, the proportion of commitment breakers is small (category iv) and has remained fairly stable. Both de facto measures show that the proportion of countries who say that they float and actually do float has increased over time whereas the proportion who say they fix and actually do fix has declined over time.

Coefficient estimates on the words and actions dummies from growth regressions are reported in Table 11. The de jure float-de facto float category is taken as the base so growth effects associated with what countries say and what they do are evaluated relative to the growth rate of de facto floaters who say they float. These regressions also include the full set of control variables used in our previous regressions.

For actions determined by effective classification, we obtain positive coefficients on the fix-fix category which although insignificant, suggest there might be some growth advantage for countries that say they fix and do relative to those who say they float and do. Similarly, negative but insignificant coefficients are obtained on the fix-float category weakly suggests that countries who break their commitment to stable currency values experience lower growth than those who say they float and do. Where we do find a statistically significant effect is on the float-fix (fear of floating) dummy. We estimate that the growth rate of countries that say they float but maintain stable currency values exceeds the growth rate of those who say and do float by 0.7 percent.

There is little evidence that discrepancies between what countries say and what they do matter for growth of industrialized countries, as none of the coefficients on the 
category dummies are significant.

For nonindustrialized countries, we estimate the growth benefit to fear of floating to be even more pronounced (and significant) at 1.12 percent above countries in the floatfloat category. The coefficient on the fix-fix category is now more precisely estimated ( $t$ statistic $=1.61, \mathrm{p}$-value $=0.053$ for one-sided test), providing marginally stronger evidence of growth advantages for countries that say they fix to carry through with fixing.

Thus, when de facto regimes are given by the effective classification, the evidence from growth regressions are largely supportive of Genberg-Swoboda's hypothesis that benefits accrue to fear of floating and the asymmetries between floating when the country says it will fix and fixing when it says it will float. When the de facto regime is given by the LYS classifications, none of the estimated slope coefficients on the category dummies are significant. For nonindustrialized countries, the coefficient on LYS fear of floating countries is negative.

\section{Conclusion}

Our effective de facto exchange rate regime classification method meets three objectives. We have designed a method that i) uses tools that are familiar to economists, ii) can replicated, modified, and updated in a straightforward manner, and iii) produces sensible results. In producing the classifications, we employed information contained in the effective exchange rate. The use of the effective exchange rate in our analysis leads to an improvement in classifying regimes and underscores the value in taking a multilateral approach in forming a generalized assessment of national policy towards exchange rate management.

Our investigation of the impact of exchange rate regimes and growth found that the highest growth to be associated with de facto fixers. This is in line with much of the extant literature and is consistent with research that has found trade benefits from currency blocs. Whether the growth advantages that we find are the result of maintaining a stable currency per se or from selection of countries that are members of trade and currency blocs is unanswered but is a problem for future research.

While the exchange rate regime adopted de facto appears to matter for growth, we also find evidence that it matters what countries say-especially if the do not do what they say. Our estimation results give the following rank-ordering of GDP growth from highest to lowest for words and actions categories: i) de jure floaters-de facto fixers first, ii) de jure fixers-de facto fixers, iii) de jure floaters-de facto floaters, and iv) de jure 
fixers-de facto floaters. Countries may have a good reason to display fear of floating since those that do experience significantly higher per capita growth. 


\section{References}

[1] Alesina, Alberto and Alexander Wagner (2003). 'Choosing (and reneging on) Exchange Rate Regimes.' NBER Working Paper 9809.

[2] Bordo, Michael D. and Marc Flandreau (2001). "Core, Periphery, Exchange Rate Regimes, and Globalization." NBER Working Paper 8584.

[3] Broda, Christian (2004). "Terms of Trade and Exchange Rate Regimes in Developing Countries." Journal of International Economics 63(1): 31-58.

[4] Calvo, Guillermo A. and Carmen Reinhart, 2002. "Fear of Floating." Quarterly Journal of Economics, CXVII(117), 379-408.

[5] Edwards, Sebastian, (2001). "Dollarization and Economic Performance: An Empirical Investigation," NBER working paper no. 8274.

[6] Edwards, Sebastian and E. Levy-Yeyati (2003). "Flexible Exchange Rates as Shock Absorbers." NBER Working Paper 9867.

[7] Frankel, Jeffrey A. (2003). " Experience of and Lessons from Exchange Rate Regimes in Emerging Economies," NBER working paper No. 10032.

[8] Frankel, Jeffrey A., Sergio L. Schmukler and Luis Serven. (2002). "Global Transmission of Interest Rates: Monetary Independence and Currency Regime." NBER Working Paper 8828.

[9] Frankel, Jeffrey A. and David Romer (2002). "Does Trade Cause Growth?" American Economic Review, 89, 379-399.

[10] Frankel, Jeffrey and Andrew Rose (2002). "An Estimate of the Effect of Common Currencies on Trade and Income," 117, 437-466.

[11] Frankel, Jeffrey and Shang-Jin Wei (1995). "Emerging Currency Blocs," in Hans Genberg, ed. The International Monetary System: Its Institutions and its Future, Springer, Berlin, 111-143.

[12] Ghosh, Atish A., Ann-Marie Gulde, Jonathan D. Ostry and Holger Wolf (2002). Exchange Rate Regimes: Choices and Consequences, Cambridge and London: MIT Press.

[13] Genberg, Hans and Alexander K. Swoboda, (2004). "Exchange-Rate Regimes: Does What Countries Say Matter?" mimeo Graduate Institute of International Studies, Geneva, Switzerland. 
[14] Juhn, Grace S. and Paolo Mauro (2002). "Long-Run Determinants of Exchange Rate Regimes: A Simple Sensitivity Analysis." IMF Working Paper 02/104.

[15] Klein, Michael W. (2002). "Dollarization and Trade," NBER working paper no. 8876.

[16] Klein, Michael W. and Jay C. Shambaugh (2004). "Fixed Exchange Rates and Trade," NBER working paper no. 10696.

[17] Levy-Yeyati, E. and F. Sturzenegger (2003). "To Float or to Fix: Evidence on the Impact of Exchange Rate Regimes on Growth." American Economic Review 93(4): 1173-93.

[18] Reinhart, Carmen M. and Kenneth S. Rogoff. 2004. "The Modern History of Exchange Rate Arrangements: A Reinterpretation," Quarterly Journal of Economics.

[19] Reinhart, Carmen M., Kenneth S. Rogoff and Miguel A. Savastano (2003). "Addicted to Dollars." NBER Working Paper 10015.

[20] Rogoff, Kenneth S., Aasim M. Husain, Ashoka Mody, Robin J. Brooks and Nienke Oomes. (2003). "Evolution and Performance of Exchange Rate Regimes." IMF Working Paper 03/243.

[21] Shambaugh, Jay C. (2004). "The Effect of Fixed Exchange Rates on Monetary Policy," Quarterly Journal of Economics, 119, 301-352. 
Table 1: Percent of slope coefficients in regression of effective exchange rate on bilateral exchange rate that indicate divergence.

\begin{tabular}{ccccc}
\hline \hline Variable & $\begin{array}{c}|\hat{\beta}-1|>0.5 \\
\text { (percent) }\end{array}$ & $\begin{array}{c}\hat{\beta}<0 \\
\text { (percent) }\end{array}$ & $\begin{array}{c}\hat{\beta}>1 \\
\text { (percent) }\end{array}$ & Nobs \\
\hline 1-month change & 87.3 & 13.4 & 2.5 & 157 \\
1-year change & 65.5 & 10.5 & 4.6 & 152 \\
4-year change & 68.1 & 15.9 & 8.0 & 138 \\
Level & 46.5 & 31.4 & - & 159 \\
\hline
\end{tabular}

Table 2: Effective Exchange Rate Classifications

\begin{tabular}{ccccccc}
\hline \hline & \multicolumn{2}{c}{ Combined } & \multicolumn{2}{c}{ Drop Bilateral } & \multicolumn{2}{c}{ Drop Effective } \\
\hline & Freq. & $\%$ & Freq. & $\%$ & Freq. & $\%$ \\
\hline 1 & 532 & 16.8 & 525 & 16.6 & 280 & 6.4 \\
2 & 116 & 3.7 & 60 & 1.9 & 0 & 0 \\
3 & 34 & 1.1 & 0 & 0 & 0 & 0 \\
4 & 811 & 25.7 & 60 & 1.9 & 233 & 5.3 \\
5 & 1602 & 50.7 & 2445 & 77.4 & 3634 & 90.0 \\
6 & 64 & 2.0 & 70 & 2.2 & 234 & 5.3 \\
\hline Nobs & 3,159 & & 3,160 & & 4,381 & \\
\hline
\end{tabular}




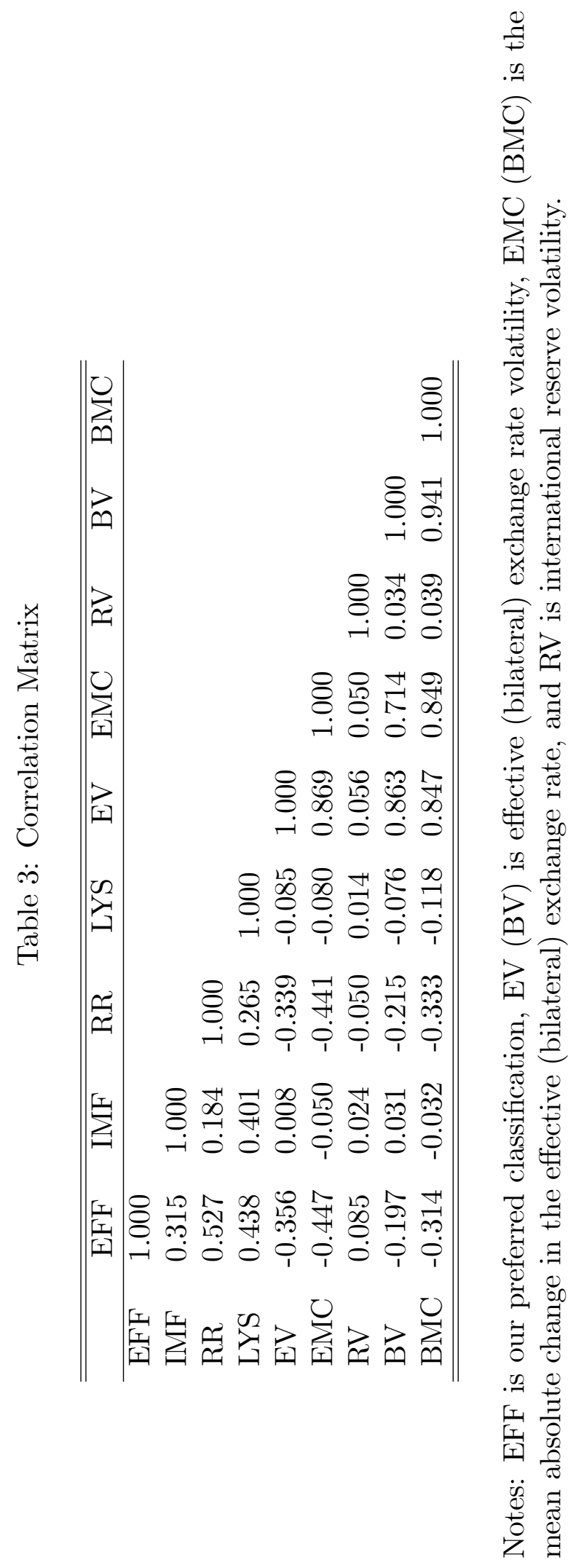


Table 4: Cross Tabulations

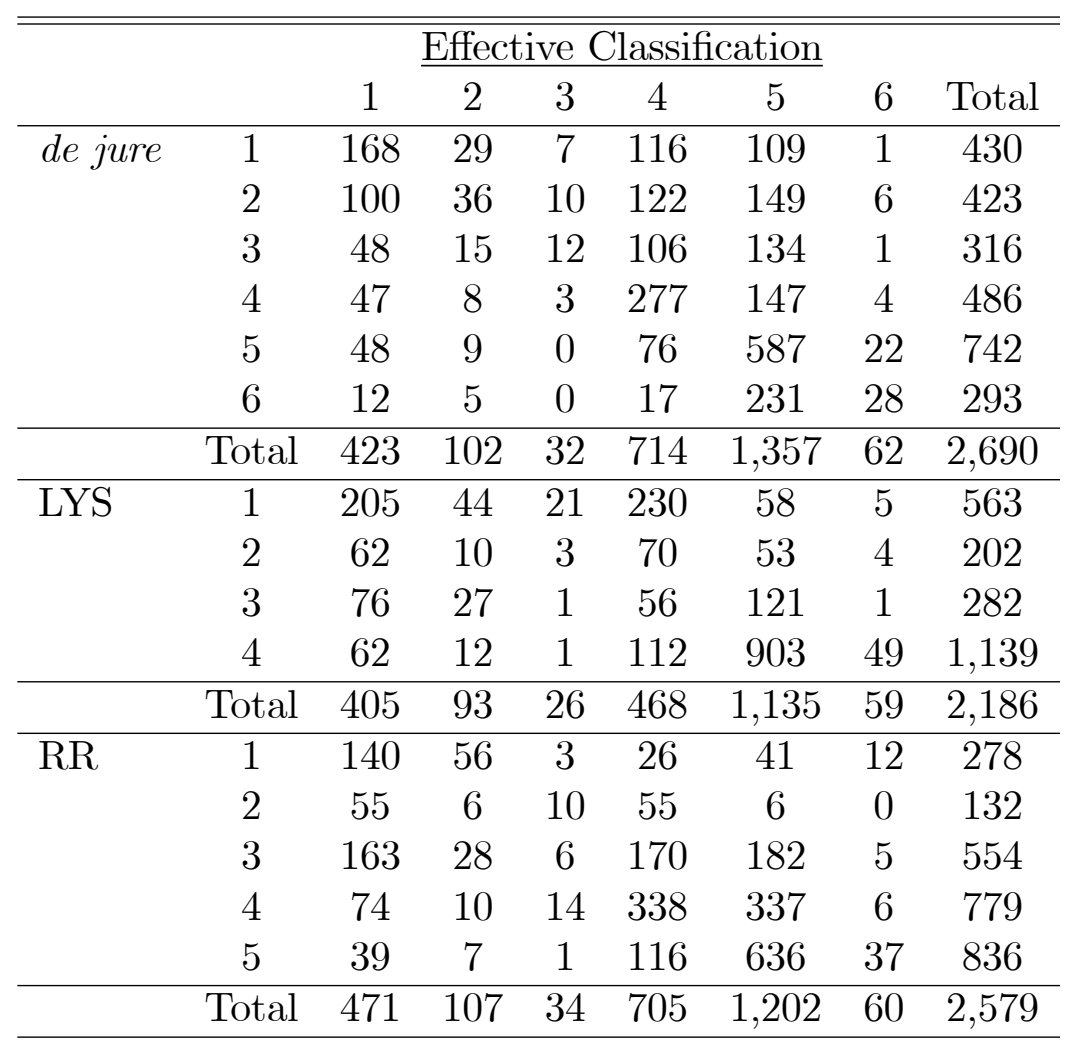

Table 5: Effective Classifications across Subgroups

\begin{tabular}{lccccccc}
\hline \hline & 1 & 2 & 3 & 4 & 5 & 6 & Total \\
\hline Non Industrial & 431 & 99 & 18 & 500 & 1,361 & 63 & 2,472 \\
(percent) & $(17)$ & $(4)$ & $(1)$ & $(20)$ & $(55)$ & $(3)$ & 100 \\
Industrial & 101 & 17 & 16 & 311 & 241 & 1 & 687 \\
(percent) & $(15)$ & $(2)$ & $(2)$ & $(45)$ & $(35)$ & $(0)$ & 100 \\
Non-crisis & 392 & 60 & 31 & 785 & 1,561 & 52 & 2,881 \\
(percent) & $(14)$ & $(2)$ & $(1)$ & $(27)$ & $(54)$ & $(2)$ & 100 \\
Crisis & 140 & 56 & 3 & 26 & 41 & 12 & 278 \\
(percent) & $(50)$ & $(20)$ & $(1)$ & $(9)$ & $(15)$ & $(4)$ & 100 \\
\hline \hline
\end{tabular}




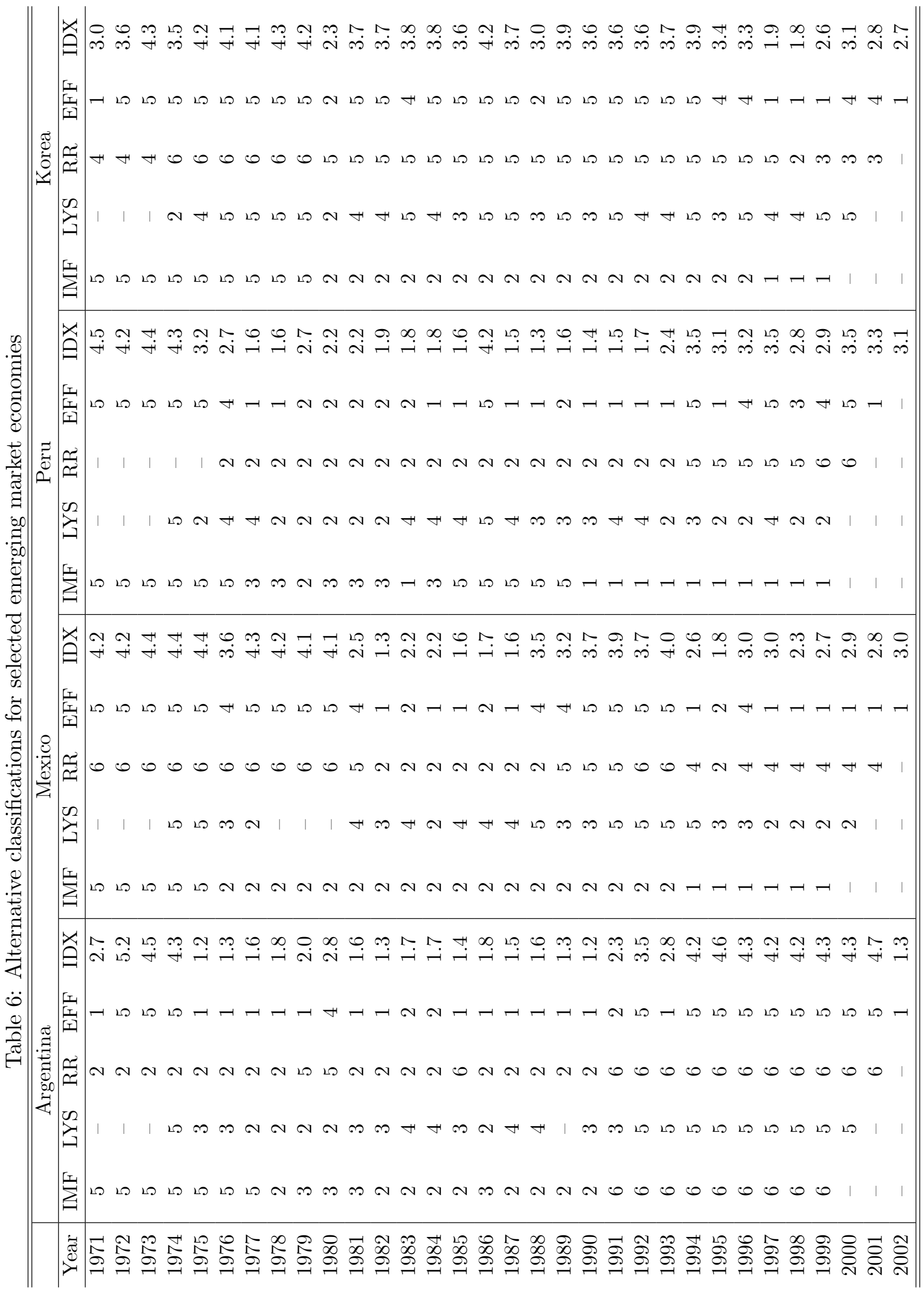


H E

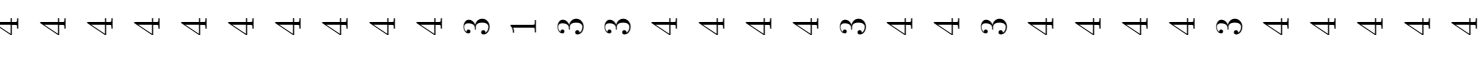
ט

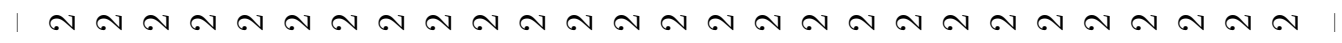



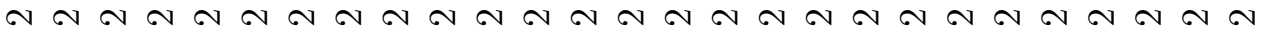

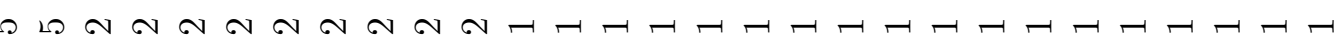

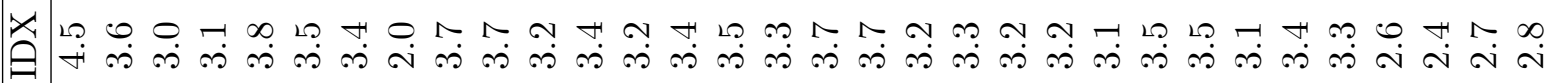

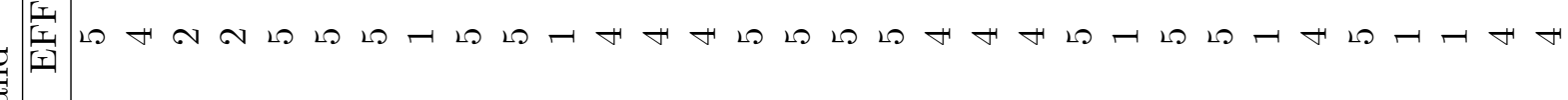

מ 20

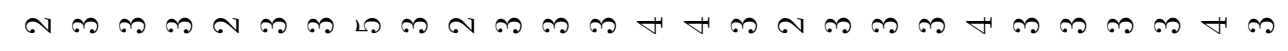

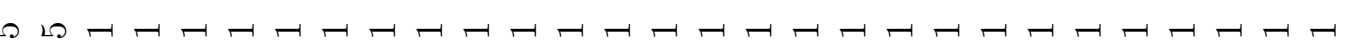

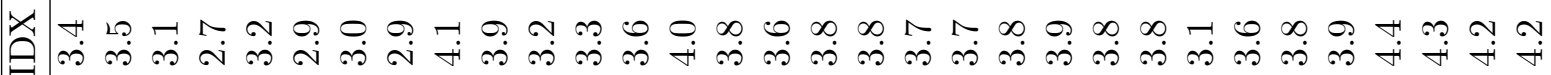

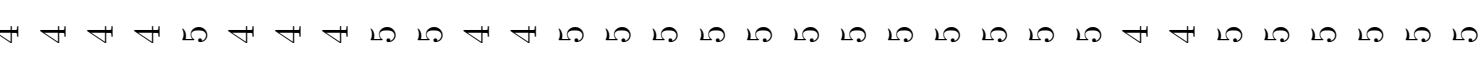



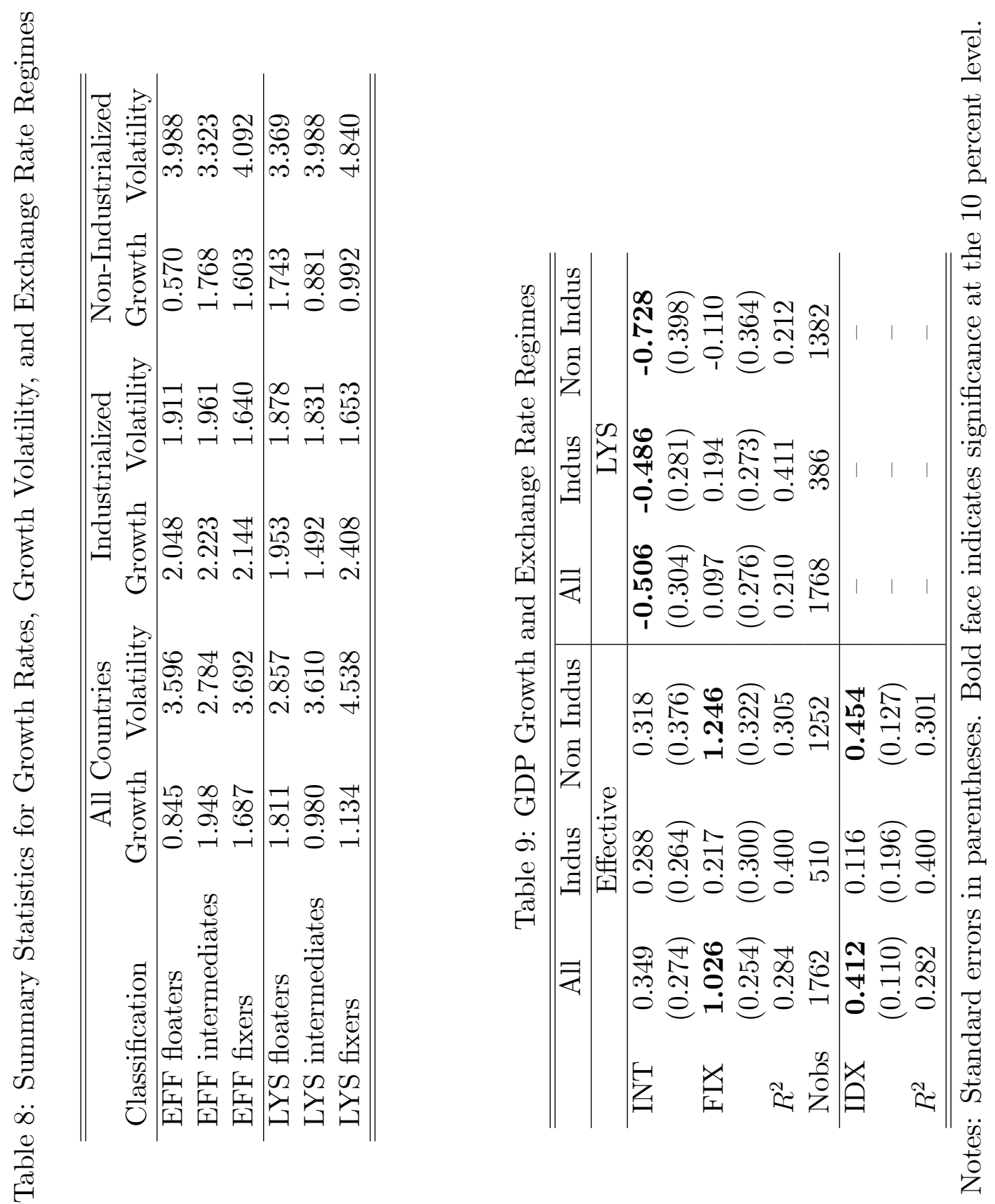
Table 10: Percentages of country-observations. De jure and effective de facto fixers and floaters tabulation.

\begin{tabular}{cccccc}
\hline \hline Sample & Nobs & $\begin{array}{c}\text { de jure Float } \\
\text { de facto Float }\end{array}$ & $\begin{array}{c}\text { de jure Fix } \\
\text { de facto Fix }\end{array}$ & $\begin{array}{c}\text { de jure Float } \\
\text { de facto Fix }\end{array}$ & $\begin{array}{c}\text { de jure Fix } \\
\text { de facto Float }\end{array}$ \\
\hline \multicolumn{7}{c}{ A. Effective } & de facto Classification \\
\hline $1971-2002$ & 2690 & 0.16 & 0.52 & 0.28 & 0.05 \\
$1971-1980$ & 816 & 0.07 & 0.72 & 0.17 & 0.05 \\
$1981-1990$ & 886 & 0.15 & 0.51 & 0.27 & 0.07 \\
$1991-2002$ & 988 & 0.23 & 0.36 & 0.37 & 0.04 \\
\hline \multicolumn{7}{c}{ B. LYS de facto Classification } \\
\hline $1971-2002$ & 2889 & 0.23 & 0.52 & 0.19 & 0.06 \\
$1971-1980$ & 730 & 0.15 & 0.69 & 0.08 & 0.07 \\
$1981-1990$ & 1058 & 0.21 & 0.55 & 0.17 & 0.08 \\
$1991-2002$ & 1101 & 0.29 & 0.37 & 0.29 & 0.05 \\
\hline \hline
\end{tabular}

Table 11: Growth, words, and actions

\begin{tabular}{c|ccc|ccc}
\hline \hline & \multicolumn{3}{|c|}{ Effective } & \multicolumn{3}{c}{ Levy-Yeyati-Sturzenegger } \\
\hline Words \& Action Categories & All & Indus & Non Indus & All & Indus & Non Indus \\
\hline de jure fix-de facto fix & 0.473 & 0.019 & 0.644 & 0.214 & -0.001 & -0.083 \\
& $(0.302)$ & $(0.318)$ & $(0.399)$ & $(0.312)$ & $(0.458)$ & $(-0.392)$ \\
de jure fix-de facto float & -0.433 & 0.208 & -0.468 & -0.361 & 0.007 & -0.779 \\
(broken commitment) & $(0.472)$ & $(1.172)$ & $(0.566)$ & $(0.434)$ & $(0.596)$ & $(0.528)$ \\
de jure float-de facto fix & $\mathbf{0 . 7 2 2}$ & 0.088 & $\mathbf{1 . 1 2 0}$ & 0.142 & 0.216 & -0.250 \\
(fear of float) & $(0.289)$ & $(0.254)$ & $(0.416)$ & $(0.298)$ & $(0.242)$ & $(0.422)$ \\
\hline$R^{2}$ & 0.204 & 0.397 & 0.302 & 0.209 & 0.402 & 0.212 \\
Nobs & 1751 & 510 & 1241 & 1758 & 386 & 1372 \\
\hline \hline
\end{tabular}

Notes: Standard errors in parentheses. Bold face indicates significance at the 10 percent level. 


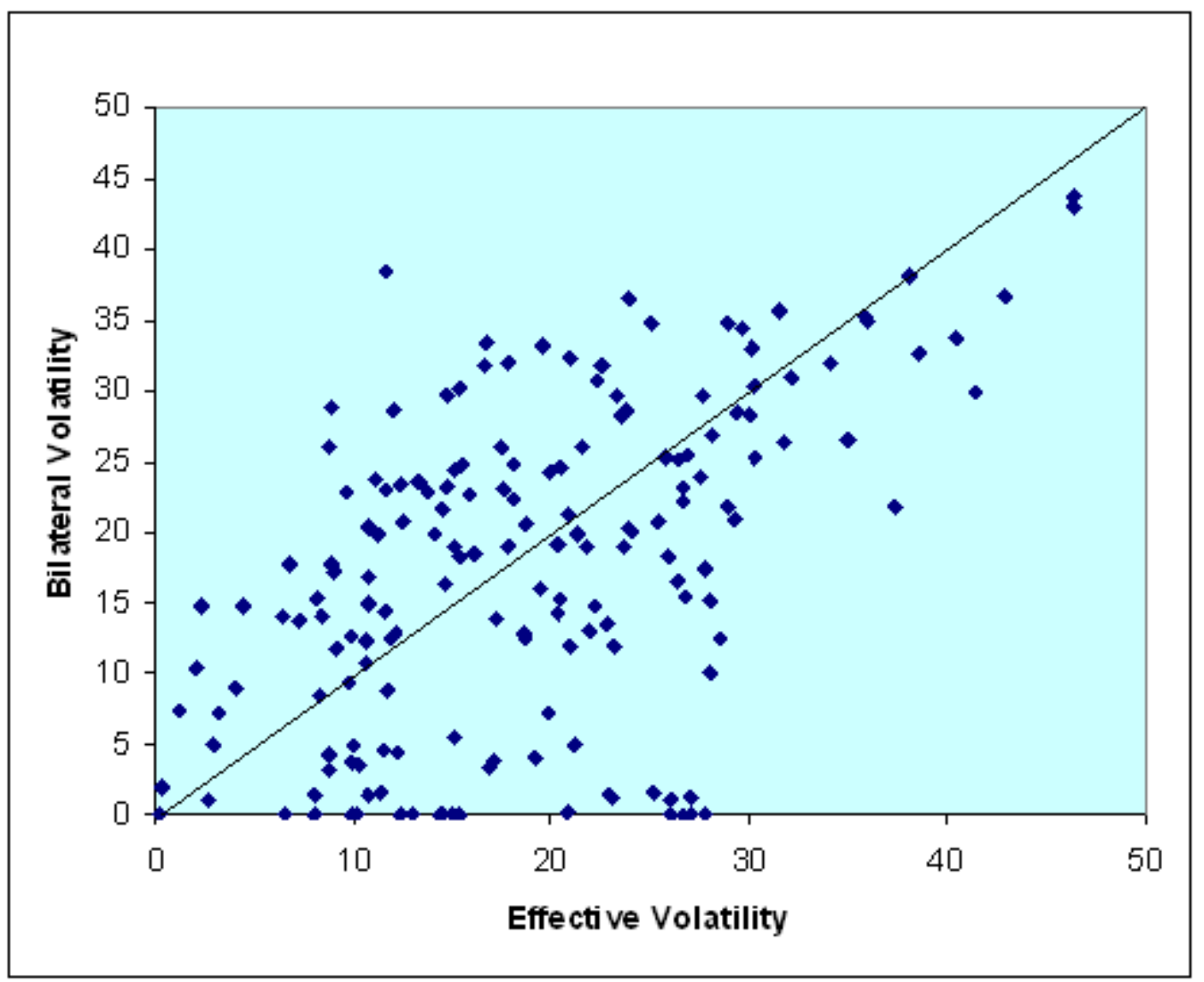

Figure 1: Scatter plots of bi-lateral exchange rate volatility against effective exchange rate volatility. 

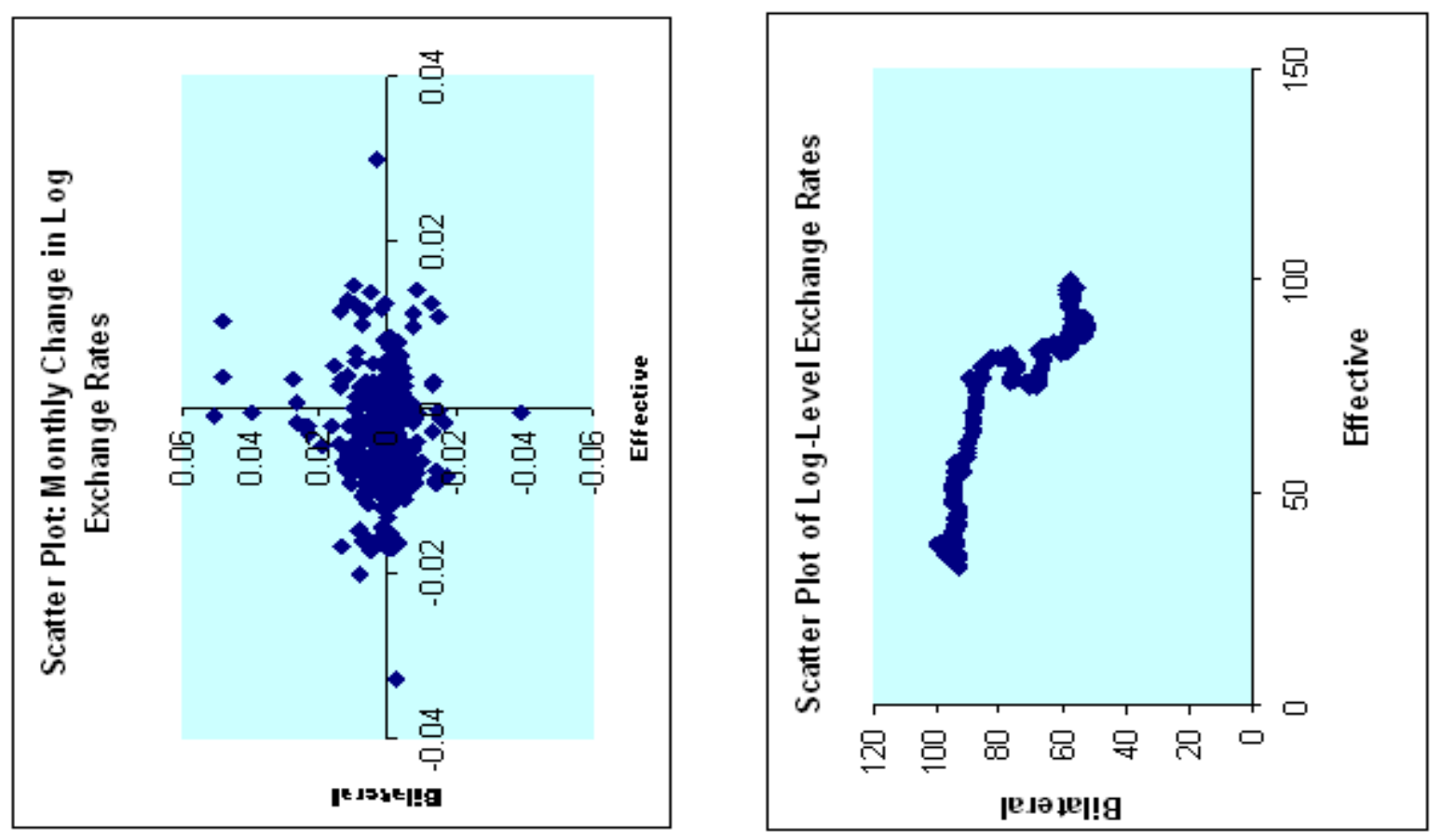

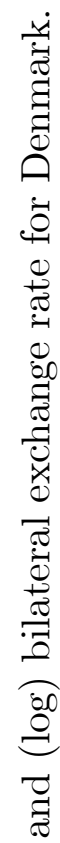
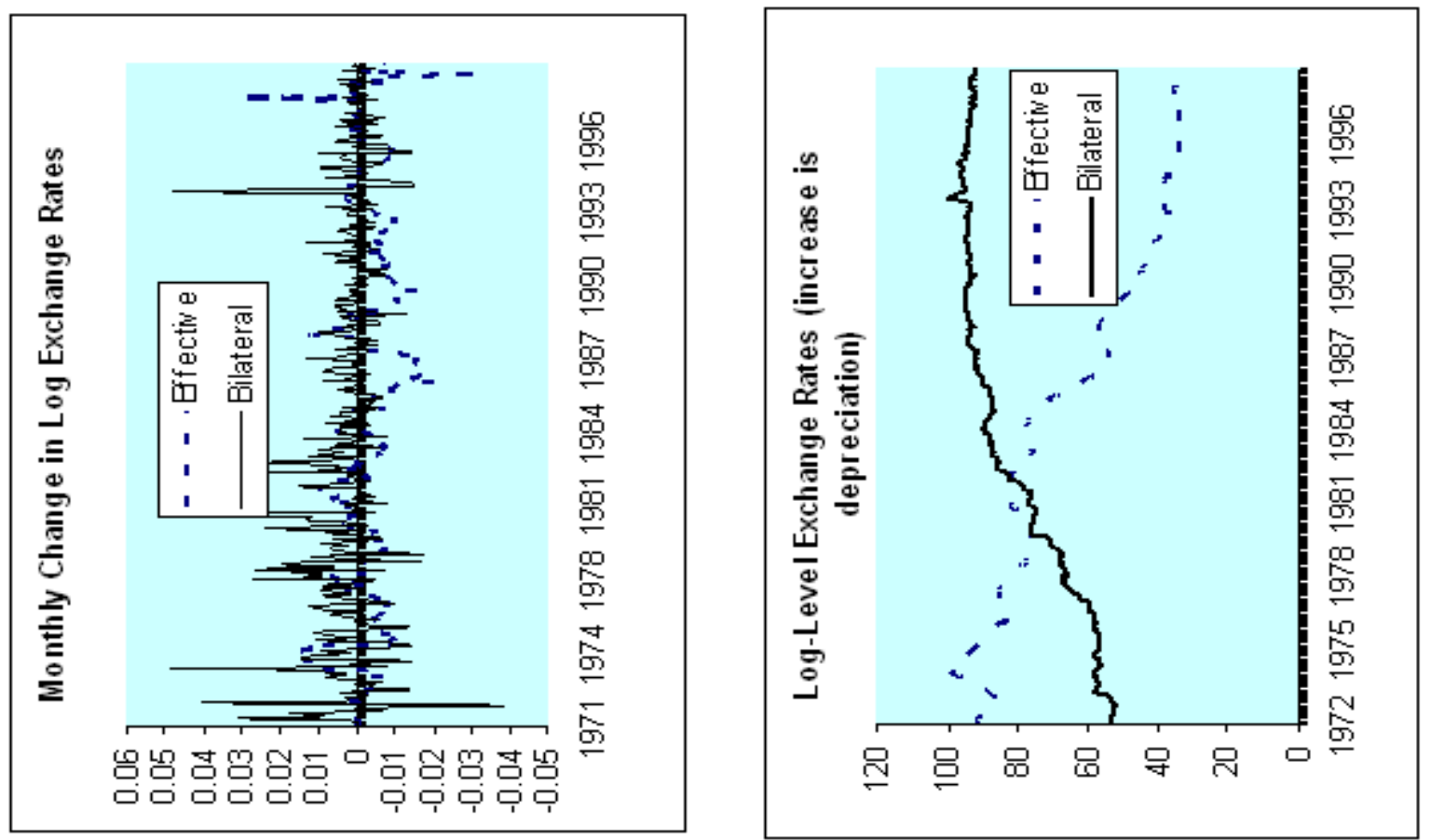

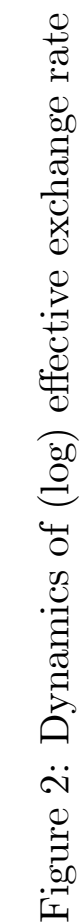



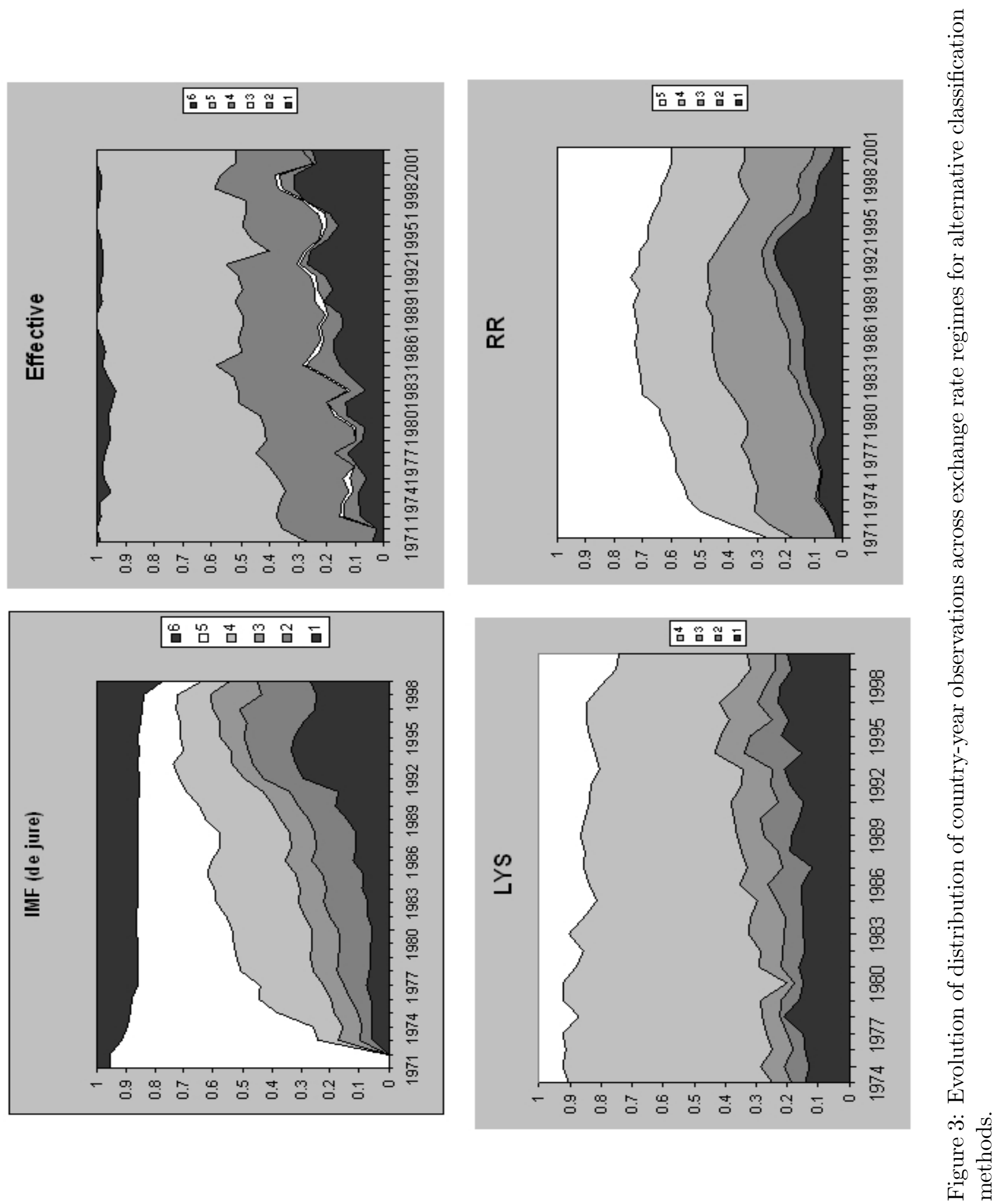


\section{Appendix}

\subsection{The Data}

Our data set includes 180 countries, each with a unique country code (1-180). Country code 182 represents the world, country code 181 represents residuals, or countries not included in the 180 .

Other notes: Fmr. Rep of Vietnam included as Vietnam in sample (cc 176), Fmr. Fed Rep of Germany (West Germany) included as Germany in sample (cc 66), Aruba, Netherlands Antilles defined together as Netherlands Antilles (cc 8) until 1987, separate thereafter, Fmr. Dem Yemen defined as Yemen in sample (cc 177), East and West Pakistan defined as Pakistan in sample (cc 124)

A monthly data set extending from 1960.01 to 2002.12 was used to construct annual volatility measures and other pieces of the annual data set. The monthly data set is comprised of the following.

Net Reserves: (in US\$) (IFS line 1L.DZF) When this data was clearly reported on a quarterly basis (i.e., at least 2 consecutive periods), the data was interpolated to get monthly data points. A full list is available upon request. Some data anomalies were discovered in the raw data. Negative reserves were observed for several months for the Central African Republic, Chad, Gabon. Negative reserves in only one month were reported for Congo, Guinea-Bissau, and Ukraine. Except for the Ukraine, these are all Central Franc Zone countries.

We note that this is not the same definition of reserves as that reported by LYS. We attempted to re-create their reserve data. They describe it as the foreign assets less foreign liabilities and central government deposits (IFS: line 11, line 16c, line 16d). These data contained many anomalies - LYS reserves are negative for 30 percent of all observations and data are partially or entirely missing for many important countries (Australia, Belgium, Brazil, France, Greece, Japan, New Zealand, Norway, Switzerland, United Kingdom). The reserve measure we utilize has approximately 10,000 more observations than LYS.

Nominal exchange rate: 2 bilateral (US\$) measures as in annual data.

Nominal effective exchange rates: Using trade weights from Comtrade data set. Additionally, to give these time series properties, they were smoothed using a 12 month moving average (5 lags, 6 leads, including observation). 
CPI: IFS (line 64..ZF) No monthly data available for USSR, Czechoslovakia. Russian monthly CPI data derived from IFS data (CPI change over previous period, line 64XX..ZF), and inserted into database. In Australia, Belize, New Zealand, Papua New Guinea, Vanuatu, the CPI is reported quarterly. These quarterly data were interpolated to obtain monthly measures using Q1 as month 3, Q2 as month 6, Q3as month 9, Q4 as month 12 .

Investment derived by using GDP (current Local currency units (LCU)) minus external balance on goods and services minus final consumption expenditure [I=GDP-NXC] (all from World Development Indicators).

Population, GDP, Exports, Imports, Terms of trade (Exports as a capacity to import), obtained from WDI.

Secondary education: WDI. Data is generally reported every 5 years in the data source which was linearly interpolated to obtain annual observations.

Civil liberties: Following LYS, these data were obtained from Freedom House country rankings. 